\title{
Nutraceutical Potential of Parkia speciosa (Stink Bean): A Current Review
}

\author{
Nur Hayati Azizul*1, Yin-Hui Leong ${ }^{2}$, Nurul Izzah Ahmad ${ }^{3}$ and Salina Abdul Rahman ${ }^{1}$ \\ ${ }^{1}$ Nutrition, Metabolic and Cardiovascular Research Centre, Institute for Medical Research, Ministry of Health, Malaysia \\ ${ }^{2}$ National Poison Centre of Malaysia, University Sains Malaysia, Malaysia \\ ${ }^{3}$ Environmental Health Research Centre, Institute for Medical Research, Ministry of Health, Malaysia
}

*Corresponding author: Nur Hayati Azizul, Nutrition, Metabolic and Cardiovascular Research Centre, Institute for Medical Research, Ministry of Health, Kompleks NIH, No. 1, Jalan Setia Murni U13/52, Seksyen U13, Setia Alam, 40170 Shah Alam, Selangor, Malaysia.

To Cite This Article: Nur Hayati Azizul. Nutraceutical Potential of Parkia speciosa (Stink Bean): A Current Review. Am J Biomed Sci \& Res. 2019 - 4(6). AJBSR.MS.ID.000842. DOI: 10.34297/AJBSR.2019.04.000842

Received: 鮆August 08, 2019; Published: 眥August 26, 2019

\begin{abstract}
Background: Inadequate fruits and vegetables intake contributes to the prevalence of major diseases such as cardiovascular diseases and cancers. Parkia speciosa [stink bean] is a common vegetable consumed in the Southeast Asia. Although it contains various phytochemicals that can help prevent disease development, the effort to develop a specific treatment or food products from Parkia speciosa remains a challenge. Here, we explore research works of the medicinal benefits of $P$. speciosa that can be used as a guide to develop future clinical studies.

Method: We conducted a database search on PubMed, Google Scholar, and Science Direct using the keywords "nutraceutical potential", "Parkia speciosa" "antioxidant", "hypoglycemic", "antitumor", "antimicrobial” and "cardiovascular effects". We included clinical trial, in vitro and in vivo studies that were written in English or Malay; and excluded review articles with no time limitations.

Result: We reviewed a total of 28 research articles. No clinical trial was found. The articles were grouped into antioxidative, hypoglycemic, antitumor, antimicrobial and cardiovascular effects. Six articles had combination of the medicinal properties. Seeds and empty pods are the most common plants parts used. Each bioactivities differed depending on the plant parts, extracts, methods, cultivar and plantation site.

Conclusion: $P$. speciosa demonstrated antioxidative, hypoglycemic, antitumor, antimicrobial and cardiovascular effects that were contributed by its phytochemical compounds. This finding could be used as a database for future clinical studies. We recommended researchers to use the information from the articles reviewed for drug development and clinical trial.
\end{abstract}

Keywords: Nutracetical potential; Parkia Speciosa; Antioxidant, Hypoglycemic; Antitumor; Antimicrobial; Cardiovascular Effects.

\section{Background}

P. speciosa or stink bean is a classic Malaysian favourite and is commonly grown and cultivated in Southeast Asia e.g. Indonesia, Malaysia, and some parts of North-Eastern India [1]. P. speciosa is also known as 'petai' in Malaysia, Singapore, and Indonesia [2], 'sator' or 'sataw' in Thailand [3], 'u'pang' in Philippines [2], and 'yongchak' in India [4]. P. speciosa earned its nickname 'stink bean' from its strong and pungent odour. The plant belongs to the pea or bean family Fabaceae and placed in Leguminosae and Mimosaceae [4]. P. speciosa contained several phytochemical compounds such as polyphenols and flavonoids [5,6], terpenoids [5,7,8], Alkaloids [5,7-10], saponins [7-10], steroids [7,8,10], tannins [7,9] and phytosterol $[11,12]$. Globally, the World Health Organization [WHO] reported that about $80 \%$ of the world population relies on traditional med icine to cure ailments [13]. In Malaysia, P. speciosa has been used traditionally to treat various diseases and ailments such as hypertension [4] and kidney disorders [14]. There is a limited data of medicinal benefits of $P$. speciosa especially on the cardiovascular and antioxidant effects. From the previous review articles, only two $[15,16]$ research experiments were included for cardiovascular effects; and only seven [15] and nine [16] research experiments were included for antioxidant effects. The findings of the current review article could be used as a database for future clinical studies. This review aimed to explore the medicinal benefits of $P$. speciosa as to provide the foundational knowledge on the topic; so that the preclinical and clinical studies can be conducted for future drug development. 


\section{Methods}

We conducted a literature search for medicinal benefits of $P$. speciosa using PubMed, Google Scholar, and Science Direct using the keywords "medicinal benefits", "Parkia speciosa" "antioxidant", "hypoglycemic", "antitumor", "antimicrobial" and "cardiovascular effects". We included clinical trials, in vitro and in vivo studies; and exclude review articles. The literature search was limited to articles published in Malay and English without time limitations.

\section{Results and Discussion}

We found a total of 28 eligible articles: 23 in vitro and 5 in vivo studies. No clinical trial was found on this topic. Of the articles reviewed, 14 articles reported on antioxidant activity, 5 articles on hypoglycemic activity, 5 articles on antitumor activity, 6 articles on antimicrobial activity and 4 articles on cardiovascular effects. There were combinations of bioactivities studied in six articles reviewed: one article documented on the antioxidant, hypoglycemic and antimicrobial activities [6], one article performed research on antioxidant and antitumor effects [17], one article reported on antioxidant and antimicrobial effects [18], two studies described both the antioxidant and antimicrobial activities $[5,18]$ and one study combined antioxidant and cardiovascular effects [19].

\section{Antioxidant activity}

A total of 13 in vitro and 1 in vivo study on the antioxidative property of $P$. speciosa were reviewed. In most of the studies cited, the seeds of $P$. speciosa were used [5,19-22] (Table 1). Other studies analysed empty pods $[6,17,23,24]$, pods $[9,18]$ and seed coat and pericarp of the P. speciosa bean [25]. The commonly used tests for antioxidative activity are 1,1-diphenyl-2-picrylhydrazyl free radical [DPPH] scavenging and reducing ferric ion antioxidant potential [FRAP] assay. Other assays used are anti-lipid peroxidation, superoxide radical scavenging activity, 2,2'-azino-bis [3-ethylbenthiazoline-6-sulfonic acid] [ABTS] radical scavenging activity and metal chelating activity. The relationship between total phenolic and flavonoid contents with antioxidant level was evaluated in four studies $[5,20,22,26]$. Two studies examined the antioxidant level indirectly $[21,25]$, whereby the antioxidant level was related to hydrogen sulphide [H2S] in one study, and the other to Heinz body inhibition [aggregation of denatured hemoglobin in the red blood cell resulting from oxidative process]. Four studies compared the antioxidant level between P. speciosa and other plants $[20,22,26]$. Generally, the antioxidant level varies depending on the part of the plant, the extraction variables [solvent-extract ratio, time, temperature and solvent type] and the plantation location.

\section{In vitro studies}

In a study by Balaji and co-workers [9], the flavonoids and phenolic content, as well as the antioxidant activity were evaluated. The flavonoids content estimation was carried out using the calorimetric method, while the phenolic content was carried out using the Folin-Ciocalteu reagent method. Reducing power assay and DPPH were used to examine the antioxidant activity. The study found that $P$. speciosa pod powder extract had $14.16 \pm 0.02 \mathrm{mg}$ gallic acid equivalents per gram [GAE/g] dry weight total phenolic content and $5.28 \pm 0.03 \mathrm{mg}$ rutin equivalents per gram [RE/g] dry weight total flavonoid content. Generally, the phenolic and flavonoid compounds are related to antioxidant activity of the plant. The extract also showed potent antioxidant activity as demonstrated by IC50 values of the extract in DPPH, $74.37 \mu \mathrm{g} / \mathrm{ml}$ compared to the standard butylatedhydroxy toluene [BHT] $35.40 \mu \mathrm{g} / \mathrm{ml}$. IC50 indicates the concentration of test extracts or positive controls that inhibit or scavenge the radical formation by $50 \%$ [23]. Although the DPPH radical scavenging activity was lower than BHT, it was evident that the extract contained a substance/s with proton-donating ability and was capable of inhibiting free radicals.

Ko and coleague [23] evaluated the antioxidant activities of aqueous and ethanolic extracts of $P$. speciosa empty pods using several assays namely: anti-lipid peroxidation, superoxide radical scavenging activity, DPPH radical scavenging activity, ABTS radical scavenging, metal chelating and reducing power. It showed that the ethanol extracts possessed stronger antioxidant activity via all the assays except for superoxide radical scavenging activity. This finding is influenced by a higher level of polyphenols [phenols and flavonoids] in the ethanolic extract. The anti-lipid peroxidation IC50 was $5.02 \pm 1.06 \mu \mathrm{g} / \mathrm{ml}$, DPPH radical scavenging activity was $64.2 \pm 3.46 \mu \mathrm{g} / \mathrm{ml}$, ABTS radical scavenging $19.6 \pm 0.44 \mu \mathrm{g} / \mathrm{ml}$, metal chelating activity $319 \pm 26.3 \mu \mathrm{g} / \mathrm{ml}$ and reducing power activity $274 \pm 16.1 \mu \mathrm{g} / \mathrm{ml}$. The extracts contained several polyphenolic constituents, the most abundant of which were gallic acid, catechin, ellagic acid and quercetin.

Two types of P. speciosa in Thailand ['Sataw-Khao' and 'Sataw-Dan'] were studied by Wonghirundecha and co-workers [18] for their total phenolic content, antioxidant and antimicrobial activities. It was found that the extraction yield, total phenolic and total flavonoid contents of 'Sataw-Dan' pod extracts were higher than that of 'Sataw-Khao' pod extracts. In contrast, 'Sataw-Khao' pod extracts showed higher DPPH [1218.07 $\pm 8.72 \mu \mathrm{mol}$ Trolox equivalent/g dry weight [TE/g] vs $920.32 \pm 6.15 \mu \mathrm{mol}$ TE/g dry weight], ABTS radical scavenging activity $[1610.67 \pm 11.88 \mu \mathrm{mol} \mathrm{TE} / \mathrm{g}$ dry weight vs $1261.14 \pm 17.44 \mu \mathrm{mol} \mathrm{TE} / \mathrm{g}$ dry weight] and metal ion chelating activity [9.76 \pm 0.03 Ethylenediaminetetraacetic acid equivalent/g dry weight [EDTAE/g] vs. 5.86 $\pm 0.02 \mathrm{EDTAE} / \mathrm{g}$ dry weight] compared to Sataw-Dan pod extracts. Thus, the authors concluded that there was no relationship between total phenolic content and antioxidant activity in the PS extract, suggesting that other phytochemicals apart from polyphenols may contribute to the antioxidant activity. In addition, both extracts showed antimicrobial effect in the form of inhibition zone formation through the agar well diffusion assay.

In a study by Aisha and co-workers [17], eight empty P. speciosa pod extracts were examined for phenolic content and anti- 
oxidant, cytotoxic and antiangiogenic activities. The results of the study showed that the methanolic sub-extract had the highest total phenolic content, $25.55 \pm 1.57 \mathrm{GAE} / 100 \mathrm{mg}$. In the DPPH scavenging assay, antioxidant activity was also highest in the methanolic sub-extract, [IC50 $26 \pm 3.0 \mu \mathrm{g} / \mathrm{ml}$ ]. It can be visualized from all the extracts used that; the antioxidant level corresponded to the total phenols content.

Sonia and co-workers [6] further explored the antioxidant, anti-inflammatory, anti- diabetic and anti-microbial activity of P speciosa. The FRAP value of the hydromethanolic extract was higher than of the ascorbic acid controls (1.9mM Ferrous sulfate (FESO4)). Its strong antioxidant activity was supported by DPPH study, as it significantly decreased in vitro DPPH radical concentration $(64.52 \pm 2.4 \%$ inhibition, IC50315.75 $\mu \mathrm{g} / \mathrm{ml})$, and hydrogen perox-

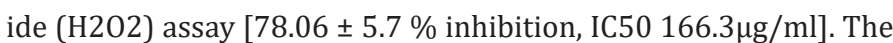
extract exhibited anti-inflammatory properties via inhibition of lipooxygenase activity (38.6 $\pm 10.2 \%$ inhibition, IC50 $493.34 \mu \mathrm{g} / \mathrm{ml}$; control $56.9 \pm 11.4 \%$ inhibition , IC50 $280.71 \mu \mathrm{g} / \mathrm{ml}$ ], proteinase inhibitory activity $(22.78 \pm 3.6 \%$ inhibition, IC50 $1142.3 \mu \mathrm{g} / \mathrm{ml}$; control $29.9 \pm 5.9 \%$ inhibition, IC50 $53.75 \mu \mathrm{g} / \mathrm{ml}$ ) and RBC membrane stabilization activity $(99.21 \pm 12.6 \%$ inhibition, IC50 $67.01 \mu \mathrm{g} / \mathrm{ml}$ ;control 99.36 $\pm 6.7 \%$ inhibition, IC50 $53.75 \mu \mathrm{g} / \mathrm{ml}$ ).

There is increasing demand for new ingredients from natural sources in the food industry. Moreover, there are suggestions to use agrowaste materials [in this case, $P$. speciosa empty pods] as functional food ingredients. Gan and Aishah [24] studied the physicochemical properties' characterization, looking at the antioxidant property of $P$. speciosa as potential functional flour. Between two method of drying [freeze dried and oven dried], different functional properties can be seen. Higher antioxidative properties were shown in freeze dried P. speciosa pod (FDPSP) which consist total phenolic content (TPC) of $110.0 \mathrm{mg}$ GAE/g sample and total flavonoid content (TFC) of $8.5 \mathrm{mg}$ pyrocatechol equivalents/g sample. These extracts [pre-diluted 50x] gave \%DPPHsc, \%ABTSsc and FRAP values of $65.3 \%, 77.4 \%$ and $1.9 \mathrm{mM}$ FESO4, respectively. Therefore, $P$. speciosa powder can be used as a substitute for commercial flour.

Five Malay raw salads namely: leaves of Cosmos caudatus ('Ulam Raja'), Oenanthe javanica ('Selom'), Murraya koenigii [curry leaf], Centella asiatica ('Pegaga) and the seeds of P. speciosa ('Petai') were studied by Reihani and Azhar [20] for their total phenolic content and antioxidant activities. The total phenolic content [mg GAE/g of plant on dry basis] were highest in Murraya koenigii (33.18) and lowest in P. speciosa (6.45). Pertaining to antioxidant property, Cosmos caudatus had the highest DPPH free radical scavenging activity (212.8) and Centella asiatica the lowest (32.4). Oenanthe javanica and Cosmos caudatus demonstrated the highest ferric reducing activities: $199.96 \mu \mathrm{mol} \mathrm{TE} / \mathrm{g}$ and $183.11 \mu \mathrm{mol}$ TE/g, respectively; while P. speciosa showed the lowest $(44.67 \mu \mathrm{mol}$ $\mathrm{TE} / \mathrm{g}$ ). It was found in this study that there was no significant correlation between antioxidant activity and total phenolic content.
This may be due to steric hindrance and presence of other reducing agents in the extracts studied.

Siow and Gan [19] examined the antioxidative bioactive peptides from $P$. speciosa seeds using alcalase. Prior to extraction, the $P$. speciosa seeds protein hydrolysate was analysed for amino acid composition. Glutamine and aspartic acid were found in the highest amounts, followed by cysteine $(154,132,84.8$ per 1000 amino acid residuals, respectively). Glutamine and aspartic acid are strong antioxidants as they act as electron donors [27]. In this study, the effects of temperature, substrate-to-enzyme ratio and incubation time were taken into consideration. The highest DPPH free radical scavenging activity and FRAP activity (2.9 mg GAE/g and $11.7 \mathrm{mM}$ FeSO4, respectively) were demonstrated in a condition of $50^{\circ} \mathrm{C}$, substrate/enzyme (S/E) ratio of 50 and 2hours incubation time. The high temperature causes unfolding of the protein molecules thus making the protein active site more accessible to the enzyme and exposes the protein donating residues. Partial hydrolysis of the proteins is essential to give higher DPPH value, compared to extensive protein hydrolysis caused by higher enzyme concentration. The DPPH values increased along with the incubation time. Upon fractionation of the protein hydrolysates that had the highest DPPH free radical scavenging activity and FRAP activity, the peptide fraction of $<10 \mathrm{k}$ Da showed the strongest bioactivities. Using advanced mass spectrometry, 29 peptide sequences were identified to be responsible for the potent bioactivities, that could be developed into novel nutraceuticals.

The production of phytochemicals in plants depends on the variety or species and external variables such as environmental conditions, agricultural practices and post-harvest handling [5]. A study by Ghasemzadeh and co-workers [5] compared the phytochemical constituents and biological activities of $P$. speciosa collected from 3 regions of Malaysia [Perak, Negeri Sembilan and Johor]. The result showed that the seeds (ethanol extract) collected from Perak contained highest phytochemical content at concentration of $100 \mu \mathrm{g} / \mathrm{mL}$, DPPH (66.29\%) and FRAP (522.1 $\mu \mathrm{M}$ of Fe (II)/g) scavenging activity, followed by Negeri Sembilan and Johor. The authors analyzed the correlation between the parameters studied and found that the antioxidative activity was significantly correlated with flavonoid content.

In another study, Maisuthisakul and co-workers [26] analyzed the correlation between parameters [yield, radical scavenging activity 1/EC50, phenolic compounds, flavonoids, moisture, ash, protein, fat, carbohydrate, dietary fibre, calcium, iron and vitamin $\mathrm{C}$ ] of 28 Thai plants. EC50 is the concentration of extract necessary to decrease DPPH radical scavenging by $50 \%$. Generally, the seeds of the plants studied had high energy, and P. speciosa seeds were among the plants with the highest energy content $(441.5 \mathrm{Kcal} / 100 \mathrm{~g}$ edible portion, $\mathrm{db}$ ). It showed antiradical activity of 1.5 (1/EC50), total phenolics of $51.9 \mathrm{mg} \mathrm{GAE} / \mathrm{g} \mathrm{db}$ and total phenolics of $20.3 \mathrm{mg}$ $\mathrm{RE} / \mathrm{g} \mathrm{db}$. The yield of extractable compounds ranged from $0.6 \%$ 
to $4.5 \%$. The yields from berries, fruit and seeds were higher than from other parts of the plants. In terms of correlation analysis, plants with high yield had high carbohydrate content and low fibre content. A high yield did not correspond to high content of phenolic compounds and high antioxidant activity. The study also revealed that plants with strong antioxidant activity had high total phenolic and flavonoid contents.

Interestingly, Liang and co-workers [21] investigated the hydrogen sulphide $\left[\mathrm{H}_{2} \mathrm{~S}\right]$ releasing capacity of ten organosulphur rich fruits and vegetables [garlic, red onion, yellow onion, scallion, shallot, leek, spring onion, Chinese chives, durian and stinky beans]. $\mathrm{H}_{2} \mathrm{~S}$ is a gaseous signaling molecule that has several effects on human health including antioxidant effect [28]. To demonstrate the importance of this gas, the authors quoted previous studies to investigate how garlic has been used as an herbal remedy for thousands of years and having cardioprotective effect. Benavides and co-workers [29] from their work in rats proposed that the two major components of garlic extract, namely diallyl trisulphide [DATS] and diallyl disulphide [DADS] are converted to $\mathrm{H}_{2} \mathrm{~S}$ resulting in relaxation of the rat aorta ring. Similarly, Chuah and co-workers [30] showed that through $\mathrm{H}_{2} \mathrm{~S}$-dependent mechanism, S-allyl cysteine, the major compound of aged garlic was able to protect against myocardial infection. In the study by Liang ang and colleagues [21], the $\mathrm{H}_{2} \mathrm{~S}$ releasing capacity of plant essential oils was evaluated by fluorescent method using $\mathrm{BCu}\left[\mathrm{H}_{2} \mathrm{~S}\right.$ selective and sensitive turn- on fluorescent probe] as probe and human breast cancer MCF- 7 cells as the medium. MCF-7 cells incubated with $\mathrm{BCu}$ for 3 hours were treated with $\mathrm{H}_{2} \mathrm{~S}$ donors to produce $\mathrm{H}_{2} \mathrm{~S}$. Fluorescence produced by $\mathrm{H}_{2} \mathrm{~S}$ captured by the probe was measured by a microplate reader. The results showed that $P$. speciosa had the highest DATS equivalent (DATS-E) value (158 mmol DATS/kg of raw material), followed by garlic (18.5mmol DATS/kg of raw material) and yellow onion (4.59 mmol DATS/kg of raw material). DATS-E value is a concept introduced in which each plate was divided into two zones; one zone loaded with different concentrations of samples, and the other zone loaded with different concentration of DATS. This method was performed to enable data comparison among different groups. Among the reasons P. speciosa had the highest DATS- E value was because of its high sulphur content, and presumably its cyclic sulphur compounds could be converted to $\mathrm{H}_{2} \mathrm{~S}$ more efficiently than linear compounds. This study indirectly relates the presence of $\mathrm{H}_{2} \mathrm{~S}$ in P. speciosa to antioxidant bioactivities.

Twenty five edible tropical plants were examined by Wong and co-workers [22] for their antioxidant properties. The total polyphenol contents, free radical scavenging, ferric ion reducing (expressed as TEAC-Trolox equivalent antioxidant capacity) and cupric ion chelating capabilities (CCA) were determined. The result showed that $P$. speciosa leaves extract had the highest TPC but showed low TEAC $_{\mathrm{DPPH}}$ and $\mathrm{TEAC}_{\mathrm{FRAP}}$. The non-correspondence between TPC and antioxidant activities is due to the fact that $P$. speciosa may contain other compounds that can oxidize the Folin-Ciocalteu, other than polyphenols. In addition, P. speciosa leaf extract chelated the cupric ions the most. This finding indicated that the extract had potential secondary compounds. TPC showed satisfactory correlation with TEAC $_{\text {DPPH }}$ and TEAC FRAP indicating that polyphenols in the extracts were partly responsible for the antioxidant activities. Conversely, TPC correlated poorly with CCA, indicating that polyphenols might not be the main cupric ion chelators.

Indirect relationship between inhibitory activity of Heinz body induction and antioxidant activity was studied by Tunsaringkarn and co-workers [25]. Hemoglobin chains undergo denaturation process through oxidative damage by reactive oxygen species and produced Heinz body, an aggregation of denatured and precipitated hemoglobin within red blood cells [31]. Hence it can be a biomarker for oxidative damage in the body. In this study, P. speciosa seed coat extracts showed the highest activity of Heinz body inhibition (39.98\%, IC25 $2.68 \mathrm{mg} / \mathrm{ml}$ ), followed by X. xylocarpa bark (42.75\%, IC25 $15.71 \mathrm{mg} / \mathrm{ml}$ ), P. speciosa Hassk. pericarp (44.89\%, IC25 28.14 $\mathrm{mg} / \mathrm{ml}$ ) and E. rheedii Spreng. seed coat (55.12\%, IC25 $33.20 \mathrm{mg} /$ $\mathrm{ml}$ ) X. xylocarpa bark, E. rheedii seed coat, Hassk seed coat, and X. xylocarpa stem contained high tannin concentration. It has been shown that the percentage of Heinz body inhibition was correlated to tannin concentration. The previous study suggested that the antioxidant activity of tannin was mainly due to iron chelation rather than hydroxide radical scavenging [32]. This finding also supported the results of the study by Wong and co-workers [22] discussed before.

\section{In vivo study}

$\mathrm{Al}$ Batran and co-workers [1] studied antioxidant and antiulcer activity of $P$. speciosa ethanolic leaf extract in ethanol-induced gastric ulcer in rats. Sprague Dawley rats were divided into 7 groups: Groups 1 and 2 received $0.5 \%$ carboxymethylcellulose (CMC) as vehicle; Group 3 received 20mg/kg omeprazole and groups 4-7 received ethanolic leaves extract of $P$. speciosa at doses of 50, 100, 200 or $400 \mathrm{mg} / \mathrm{kg}$. After 1 hour, CMC or absolute ethanol was administered to groups 2-7. The rats were euthanized after 1 hour and the gastric mucosa was examined for gastric juice acidity, gastric wall mucus, macroscopic gastric lesion evaluation, antioxidant activity, histological examination and immunohistochemical staining. Regarding the antioxidant activity, gastric tissue homogenate prepared from the groups that were treated with plant extract displayed significant antioxidant activity, with decreased levels of malondialdehyde (MDA) and elevated levels of total glutathione (GSH) and superoxide dismutase (SOD), in response to oxidative stress due to ethanol treatment. MDA is the final product of lipid peroxidation which causes a loss of membrane fluidity, impaired ion transport and membrane integrity resulting in loss of cellular function [33]. It was found that the groups treated with the plant extract reduced this process. GSH plays a role in determining ulcer severity and acts as tissue protective agent [34,35]. SOD converts superoxide to hydrogen peroxide $\left(\mathrm{H}_{2} \mathrm{O}_{2}\right)$, which is transformed into 
water by catalase in the lysosomes or by glutathione peroxidase in the mitochondria [36].

\section{Hypoglycemic Activity}

There were 5 articles that demonstrated the hypoglycemic property of $P$. speciosa, 2 in vitro and another 3 in vivo studies. One of the in vitro hypoglycemic studies has been discussed earlier by Sonia and co-workers [6] as part of their study. Two studies examined empty pods and seeds separately $[37,38]$, one study examined seeds and pericarp separately [39] and two studies examined empty pod $[6,11]$. Among the assays used were $\alpha$-glucosidase inhibition activity, alpha amylase inhibition activity, and porcine pancreatic lipase (PPL) inhibition assay and glucose oxidase method. All five studies exhibited a strong hypoglycemic activity of the plant. Two studies explored the compounds responsible for the hypoglycemic activity $[11,38]$. There was some inconsistency on parts of the plant that gives greater hypoglycemic effect. Tunsaringkarn and colleagues [39] found that the P. speciosa pericarp had a higher hypoglycemic activity than the seeds, but Jamaluddin and colleagues $[37,38]$ had opposite findings. This inconsistency could be due to the cultivar, harvesting time and method, types of extract and assays performed.

\section{In vitro study}

A study by Tunsaringkarn and colleagues [39] evaluated twenty species of Thai plants of Mimosaceae family. $\alpha$-glucosidase is the enzyme responsible for digestion of polysaccharide and oligosaccharide to monosaccharides [40]. Using $\alpha$-glucosidase inhibition assay, $P$. speciosa pericarp was one of the plants that showed high inhibition activity; IC50 $0.0581 \mathrm{mg} / \mathrm{ml}$ (89.46\%). As a comparison other plants had $\alpha$-glucosidase inhibition of: Entada rheedii seed coat IC50 0.0043, Archidendron jiringa seed coat IC50 0.0054, Albizia lebbeck branch bark IC50 0.0397 and Albizia lebbeckoides bark IC50 $0.0702 \mathrm{mg} / \mathrm{ml}$. P. speciosa seed showed lower percentage of $\alpha$ glucosidase inhibition activity (45.72\%).

Sonia and co-workers [6] studied the anti- diabetic activity of $P$. speciosa empty pods via two assays: alpha amylase inhibition and porcine pancreatic lipase (PPL) inhibitory assay. The alpha amylase acts to hydrolyze dietary starch [maltose] to glucose. In this study, the researchers explored how the P. speciosa pod extract can inhibit alpha amylase resulting in reduction of post prandial hyperglycemia. It was found that $P$. speciosa showed a maximum inhibition of $79.2 \%$ at $500 \mathrm{ug} / \mathrm{ml}$. The extract exhibited anti- diabetic property as the IC50 of $P$. speciosa were found to be $199.29 \mu \mathrm{g} / \mathrm{ml}$ compared to standard acarbose $(324.18 \mu \mathrm{g} / \mathrm{ml})$. From another aspect, pancreatic lipase functions to digest dietary fat, specifically hydrolyzing triacylglycerol to 2-monoacylglycerol and fatty acids. Through PPL inhibitory assay, the maximum inhibitory activity of $P$. speciosa extract at $500 \mathrm{ug} / \mathrm{ml}$ was $89.5 \%$; IC50196.61 $\mathrm{\mu g} / \mathrm{ml}$ compared to Orlistat, $76.3 \%$; IC50227.27 $\mu \mathrm{g} / \mathrm{ml}$.

\section{In vivo studies}

Jamaludin \& Mohamed [37] studied the hypoglycemic effect of $P$. speciosa extracts using glucose oxidase method. In this study, healthy Sprague Dawley rats were induced to be diabetic via intravenous injection of $60 \mathrm{mg} / \mathrm{kg}$ alloxan. The two groups of normal and alloxan-induced diabetic rats were given the $P$. speciosa extract in the range of $25-500 \mathrm{mg}$ extract/ kg body weight (BW), together with $1 \mathrm{~g}$ glucose/kg BW of rat. The result showed that only the chloroform extracts from both the empty pods and seeds had a strong hypoglycemic activity on diabetic rats. The seed had a higher hypoglycemic activity than the pod. The reduction of blood glucose in alloxan diabetic rats given $0.4 \mathrm{~g} / \mathrm{kg}$ P. speciosa pod and seed were $36 \%$ and $57 \%$, respectively. The hypoglycemic action took place as early as within an hour, best after 2 hours and lasted for at least 24 hours. The study also revealed the dose-response relationship of $P$. speciosa seed on blood glucose level. Maximum reduction of blood glucose was seen with $500 \mathrm{mg} / \mathrm{kg}$ BW [77\% decrement]. Optimum dosage seen was $200 \mathrm{mg} / \mathrm{kg}$ BW. There was insignificant raise of blood glucose levels of normal rats fed with $0.4 \mathrm{~g}$ seed or pod extracts.

As an extension of the above study, Jamaludin and co-workers [38] explored further on the actual compound contributing to the hypoglycemic effect of $P$. speciosa seeds. The hypoglycemic fraction S-9.4 was identified through chromatographic separation. The fraction showed $83 \%$ reduction of blood glucose at $100 \mathrm{mg} / \mathrm{kg} \mathrm{BW}$, compared to $111 \%$ reduction of blood glucose at $5 \mathrm{mg}$ glibenclamide $/ \mathrm{kg}$ BW. The minimum effective dose was $25 \mathrm{mg} / \mathrm{kg}$ BW. The fraction was found to contain mixture of $\beta$-sitosterol (66\%) and stigmasterol (34\%). Interestingly, the two sterols exhibited synergistic effect. No hypoglycemic effect produced when the sterols were tested individually.

The similar author, Jamaludin and co-workers [11] identified component P-7.1 (stigmast-4-en-3-one) as the compound responsible in producing hypoglycemic activity of pod extract. Compared to $111 \%$ blood glucose reduction by $5 \mathrm{mg} / \mathrm{kg}$ BW glibenclamide, $100 \mathrm{mg} / \mathrm{kg}$ BW of P-7.1 reduced the glucose levels by $84 \%$. The minimum effective dose was $50 \mathrm{mg}$ empty pods $/ \mathrm{kg}$. The extract at $400 \mathrm{mg} / \mathrm{kg}$ BW did not significantly change the blood glucose levels in normally fed rats.

\section{Antitumor/Antimutagenicity}

We found five articles highlighting the antitumor activity of the plant. Several terms including antimutagenicity, antiproliferation and antiangiogenic were combined as to describe antitumor activity. All of the articles were in vitro studies. One of the studies by Aisha and colleagues [17] has been mentioned earlier in antioxidant activity. Three articles used $P$. speciosa seed [41-43], one article used empty pods [17] and one article used pericarp and seed coat [44]. Various techniques have been used to demonstrate the antitumor activity such as Epstein-Barr virus (EBV) inhibitory as- 
say [41], Ames preincubation method against Trp-P-1 in Salmonella typhimurium TA98 [42], thioproline determination [43], Peripheral Blood Mononuclear Cell (PBMC) culture and 2,3-bis-(2-methoxy4-nitro-5-sulfophenyl)-2H-tetrazolium-5-carboxanilide (XTT) cell proliferation test [44]; and using rat aortic rings, matrigel matrix with Human Umbilical Vein Endothelial Cells [HUVEC] and Vascular Endothelial Growth Factor (VEGF) level [17]. Effect of thermal processing to the antitumor activity was assessed in two studies $[42,43]$. All articles demonstrated positive antitumor activity of $P$. speciosa.

\section{In vitro studies}

Murakami and colleagues [41] studied the antitumor activities of 114 methanol extracts of edible Malaysia plants for their antitumor activity towards tumor promoter HPA-induced Epstein Barr Virus (EBV)activation in Raji cells. EBV activation was evaluated by detecting early antigen (EA) which was stained with high titre EApositive sera from nasopharyngeal carcinoma patients. The results were ranked into 4 categories, based on inhibitory rate (IR) toward EBV activation and cell viability (CV): +++ strongly active (IR $\geq 70 \%$ and /or 50\% >CV); ++ moderately active $(70 \%>$ IR $\geq 50 \%$ and CV $\geq 50 \%)$; + weakly active ( $50 \%>$ IR $\geq 30 \%$ and CV $\geq 50 \%$ )and - inactive $(30 \%>$ IR and $C V \geq 50 \%)$ P. speciosa showed weakly active inhibitory rate towards tumor promoter HPA-induced Epstein Barr Virus (EBV) activation, with $45 \%$ IR and $>90 \% \mathrm{CV}$. Of the samples studied, 32\% [37 samples] showed strongly active, 25\% (28 samples) moderately active and $17 \%$ (19 samples) weakly active inhibitory action.

Research study done by Tangkanakul and co-workers [42] examined 10 foods in central and southern Thailand containing local Thai vegetables. Methanol extracts of both the raw ingredients and homogenized foods were evaluated for antioxidant activity using DPPH scavenging assay and antimutagenic assay using Ames preincubation method (against Trp-P-1 in Salmonella typhimurium TA98). Total phenolic content was determined using the FolinCiocalteau reagent. Raw P. speciosa showed antioxidant activity of $0.04 \mathrm{~g}$ vitamin $\mathrm{C}$ equivalent / 100g [VCE/100 g], total phenolic content of $0.13 \mathrm{~g}$ GAE/100 g and 31\% inhibition against Trp-P-1. A strong antimutagenicity was demonstrated by galangal, lemongrass, wild betal, turmeric and kaffir lime leaf (87-97\%). Both antioxidant activity and antimutagenicity increased after the plant was cooked. The antioxidant activity increased from $0.04 \mathrm{~g} \mathrm{VCE} / 100 \mathrm{~g}$ to $0.14 \mathrm{gVCE} / 100 \mathrm{~g}$, and the the antimutagenic activity increased from $31 \%-69 \%$. This result showed benefit of cooking to enhance both bioactivities.

Thioproline or thiazolidine-4-carboxylic acid (TCA) is a sulphur-containing amino acid, produced from condensation of formaldehyde and cysteine. It was documented as an effective nitrite-trapping agent in human body, thus inhibiting the endogenous formation of carcinogenic N-nitroso compounds [45]. In this experiment, Suvachittanont and colleague [43] evaluated the formaldehyde, thiol and TCA level in various edible leguminous seeds in
Thailand. The uncooked $P$. speciosa was found to have the highest level of formaldehyde $[0.77 \pm 0.07 \mathrm{mmol} / 100 \mathrm{~g}]$, which decreased upon boiling [0.25 $\pm 0.18 \mathrm{mmol} / 100 \mathrm{~g}$ ]. This observation could be due to volatilization of formaldehyde and formation of TCA upon boiling. Consistently, the TCA content of uncooked P. speciosa was $<0.001 \mathrm{mmol} / 100 \mathrm{~g}$ dry beans and it increased to $0.14 \pm 0.02$ mmol/100 g dry beans after boiling. The highest level of TCA was found in Archidendron clypearia ['Niang Nok'] both in uncooked and cooked status.

In subsequent study, Tunsaringkarn and colleague [44] evaluated the antiproliferation activity of human white blood cells, Peripheral Blood Mononuclear Cell (PBMC) with 21 Thai Mimosaceous plant extracts. P. speciosa pericarp and seed coat were among plants with high inhibitory cell proliferation $(17.17 \%$ and $12.16 \%$, respectively). The researchers correlated the high inhibitory effect with tannin level, which was also consistently high, $250 \mathrm{mg} / \mathrm{g}$ in Parkia speciosa pericarp and $350 \mathrm{mg} / \mathrm{g}$ in Parkia speciosa seed coat. This finding suggested tannin as potential cancer therapeutic agent.

In the assessments of antiangiogenic activity, the methanolic extract and all its sub-extracts showed more than 50\% inhibition of rat aortic microvessel outgrowth [17]. P speciosa extracts also inhibited tube formation on matrigel matrix involving HUVECs ( $\mathrm{Hu}-$ man Umbilical Vein Endothelial cells). Under light microscopy, the HUVECs treated with $P$. speciosa extracts showed formation of cytoplasmic vacuoles, which are markers of autophagy as a result of nutritional deprivation which is essential to maintain cell viability [46]. The vascular endothelial growth factor (VEGF) concentration of treated HUVECs was also reduced, $(36 \pm 2.2 \mathrm{pg} / \mathrm{ml})$ compared to $51 \pm 1.6 \mathrm{pg} / \mathrm{ml}$ in untreated cells. The extracts did not show acute toxicity.

\section{Antimicrobial activity}

We found six articles on this bioactivity, and all were in vitro studies. Three studies have also experimented on the antioxidant studies described earlier $[5,6,18]$. Main methods used in the experiments were agar-well diffusion assay and disc diffusion method.

\section{In vitro studies}

Uyub and co-workers [47] reported that the extracts of $P$. speciosa seeds in petroleum ether, chloroform, and methanol demonstrated antibacterial activity against Helicobacter pylori but none was found in the water extract. The activity was found highest in the chloroform extract followed by methanol and petroleum ether. In comparison, the chloroform extract of $P$. speciosa showed a moderate inhibition zone diameter to mg extract ratio (25.0), compared to other plant extracts where the ratios were in the range of 1.5117.5 .

In the study of Sakunpak and Panichayupakaranant [48], amongst the forty-four extracts of twenty-two Thai edible plants that were investigated for antibacterial activity using the disc diffusion method, the methanolic P. speciosa seed extract was found be able to inhibit Helicobacter pylori growth, while the ethyl acetate 
extract was effective against Escherichia coli. These extracts, however, had no inhibitory effect on Salmonella typhimurium, Salmonella typhi, and Shigella sonnei growth. According to Gmelin and co-worker [49], two cyclic polysulfide compounds, hexathionine and trithiolane in the P. speciosa seeds are contributing to its antibacterial property.

In Thailand, the 'Sataw' or P. speciosa pods extract could be potentially used as a natural preservative [18]. Both 'Sataw-Khao' and 'Sataw-Dan' pod extracts under investigated by the same group of researchers showed antimicrobial activity against food-borne pathogenic bacteria (Bacillus cereus, Listeria monocytogenes, Staphylococcus aureus, Escherichia coli, Salmonella typhimurium, Vibrio cholerae non 01/ non 0139) and food spoilage bacteria (Aeromonas hydrophila, Pseudomonas aeruginosa, Serratia marcescens). Although there were no significant differences between 'Sataw-Khao' and 'Sataw-Dan' pod extracts against all the tested bacteria, but for Gram negative bacteria, the extracts exhibited a lower range of inhibition zone than Gram positive bacteria. However, the result is not in favour for Vibrio cholerae which was the most susceptible strain in comparison with other tested Gram-negative bacteria. These results are in agreement with the findings of Musa and co-workers [50] who observed that $P$. speciosa extract could be effective against all Gram-positive bacteria [Streptococcus agalatiae, S. aeruginosa and $S$. aureus] and some Gram-negative bacteria (A. hydrophila and V. parahaemolyticus). However, the Gram-negative bacteria including Citrobacter freundii, Edwardsiella tarda, E. coli and V. alginolyticus were resisted to the extract.

Similar findings were reported by Sonia and co-workers [6], whereby the methanolic extract of $P$. speciosa pod showed the inhibition against common pathogens [Staphylococcus aureus, Escherichia coli, Pseudomonas aeruginosa and Klebsiella pneumoniae]. The highest zone of inhibition was demonstrated for the gram-positive Staphylococcus aureus at $10 \mathrm{~mm}$. The bioactive compounds are responsible to effectively inhibit and/or stop microbial growth via disruption of the synthesis of microbial nucleic acids, proteins and cell walls [51]. According to the previous studies, P. speciosa pod extract could inhibit all tested pathogenic and spoilage bacteria compared to rambutan peel, mangosteen peel, palmyra peel and coconut husk [52], rambutan peel and seed [53], pomelo peel [54] and banana peel [55] which could only inhibit certain bacteria and their inhibition zones were reported to be inferior to the P. speciosa extract.

Fatimah [56] studied the utilization of $P$. speciosa pod extract as reducing agent in silver nanoparticles (Ag NPs) synthesis and its potential as antimicrobial agent. She reported that the microwave-assisted synthesis of Ag NPs using P. speciosa pod extract demonstrated antibacterial activity against Escherichia coli, Staphylococcus aureus, and Pseudomonas aeruginosa. The specific compounds that act as reducing agents and support the antimicrobial activity of Ag NPs are generally flavonoids and polyphenol compounds.
From the comparison study done by Ghasemzadeh and co-workers [5], P. speciosa extract from Perak had a strong inhibitory effect towards both Gram positive and Gram-negative bacteria. The bacterial strains that were most susceptible to P. speciosa extract were Staphylococcus aureus $[7.2 \pm 0.346 \mathrm{~mm}$ inhibition zone, minimal inhibitory concentration of $40.0 \mu \mathrm{g} / \mathrm{ml}$ ] and Bacillus subtilis $[8.4 \pm 0.320 \mathrm{~mm}$ inhibition zone, minimal inhibitory concentration of $40.0 \mu \mathrm{g} / \mathrm{ml}$. The Gram-negative bacteria were less sensitive to the extracts compared to Gram positive, due to the presence of a cell wall that prevents permeation of the extract into the cell. The antibacterial activity was correlated to the effect of gallic acid.

\section{Effects on Cardiovascular system}

Four articles were reviewed for the effects of P. speciosa on cardiovascular system. Three research studies done in vitro involving human umbilical vein endothelial cells [HUVECs], cardiomyocytes (cells of the heart) and Angiotensin-converting enzyme (ACE) $[19,57,58]$. The other study was done in vivo [59]. One study also experimented antioxidant activity [described in the antioxidant section] [19]. Three of the articles used empty pod extracts [57-59] and one article used seed [19]. The chemical agents used apart from $P$. speciosa extract were tumor necrosis factor- $\alpha$ (TNF- $\alpha$ ), quercetin, nicardipine, N(G)-nitro-L-arginine methyl ester (L-NAME) and ACE solution. Among the outcomes observed are the inflammatory protein expressions: nuclear factor kappa B cell (NFkB) p65, p38 mitogen-activated protein kinase [p38 MAPK) , inducible nitric oxide synthase (iNOS), cyclooxygenase-2 (COX-2) and vascular cell adhesion molecule-1 (VCAM-1) [57,58]; blood pressure level, plasma nitric oxide level, cardiac angiotensin converting enzyme (ACE) inhibitory activity, NADPH oxidase activity and cardiac lipid peroxidation content [59]. The outcome proved cardioprotective effect of the P. speciosa extract.

\section{In vitro studies}

As a basis of understanding, TNF- $\alpha$ is a proinflammatory cytokine that has been used in many in vitro studies to induce inflammation [57]. It stimulates inflammatory markers, such as iNOS, nitric oxide [NO], COX-2 and VCAM-1, through [NFKB] pathway activation [60]. NFKB induces cardiomyocyte hypertrophy [61]. In addition, p38 MAPK was also described to be involved in the inflammatory process by triggering the synthesis of inflammatory regulators such as TNF- $\alpha$ and COX-2 [62]. Elevated p38 MAPK activity resulted in augmented inflammatory, hypertrophic and fibrotic processes in patients with end-stage heart failure and ischemic heart disease [63].

Mustafa and colleague [57] studied the anti-inflammatory activity of $P$. speciosa empty pod extract in human umbilical vein endothelial cells [HUVECs]. HUVECs were divided into four groups: HUVECs exposed to TNF- $\alpha[10 \mathrm{ng} / \mathrm{ml}]$ in the presence $[25 \mathrm{ug} / \mathrm{ml}]$ or absence of $P$. speciosa extract. Quercetin act as positive control while HUVECs without TNF- $\alpha$ served as negative control. The concentration of the P. speciosa extract was chosen at $25 \mathrm{ug} / \mathrm{ml}$ because 
of its highest cell viability in HUVECs co-incubated with TNF- $\alpha$. Quercetin was used as the positive control as it was present in the extract. All the inflammatory protein expressions were reduced in HUVECs with P. speciosa extract, namely NFkB p65, iNOS, COX-2 and VCAM-1, as determined with Western blot analysis. The nitric oxide [NO] and reactive oxygen species [ROS] level were also decreased [10.24uM and 120\%, respectively]. These effects were comparable to that of quercetin. This observation was demonstrated as $P$. specios $a$ extract attenuates TNF- $\alpha$-induced inflammatory responses by blocking the activation of $\mathrm{NF} \kappa \mathrm{B}$ p 65 and thus reduces the iNOS, COX-2 and VCAM-1 expressions as well as ROS and NO production.

A relatively similar study design was performed by Gui and colleague [58], in which inflammation-induced cardiomyocytes were used to determine the anti-inflammatory property of $P$. speciosa extract. The researchers proposed that the anti-inflammatory effect of $P$. speciosa were due to modulation of NFKB and MAPK pathways. The cardiomyocytes were divided into four groups: negative control, cardiomyocytes exposed to TNF- $\alpha$, cardiomyocytes exposed to P. speciosa extract and TNF- $\alpha$ and cardiomyocytes exposed to quercetin and TNF- $\alpha$. The P. speciosa extract $[500 \mathrm{ug} / \mathrm{ml}]$ and quercetin [1000uM] used were different in quantity compared to the previous study. The NFkB p65 and p38 MAPK expression were reduced in cardiomyocytes pre-treated with $P$. speciosa extract or quercetin. Similarly, the iNOS, COX-2 and VCAM-1 expression as well as NO and ROS levels were also reduced. This effect confirmed the postulation and could be attributable to the polyphenol content of $P$. speciosa, specifically quercetin.

Using alcalase, Siow and Gan [19] examined the antihypertensive bioactive peptides from $P$. speciosa seeds. Amino acids such as isoleucine, valine, phenylalanine and tyrosine contributed to the angiotensin converting enzyme [ACE]- inhibitory activity. A comparison of the ACE-inhibitory activity was made between different temperature, substrate-to-enzyme $[\mathrm{S} / \mathrm{E}]$ ratio and incubation time. The highest percentage of ACE- inhibitory activities [80.2\%] were demonstrated in a condition of $50^{\circ} \mathrm{C}, \mathrm{S} / \mathrm{E}$ ratio of 50 and 2 hours incubation time.

\section{In vivo studies}

Kamisah and colleague [59] experimented the effects of $P$. speciosa empty pod extract in rats given $\mathrm{N}(\mathrm{G})$-nitro-L-arginine methyl ester (L-NAME). L-NAME is an inhibitor of nitric oxide synthase. It reduces plasma nitric oxide and increases systolic blood pressure [due to relaxation of blood vessel], ACE and NADPH oxidase activities, as well as lipid peroxidation in the heart [59]. Twenty-four

\begin{tabular}{|c|c|}
\hline \multicolumn{2}{|l|}{ Table 1: List of Abbreviations. } \\
\hline DPPH & 1,1-DIPHENYL-2-PICRYLHYDRAZYL FREE RADICAL \\
\hline FRAP & REDUCING FERRIC ION ANTIOXIDANT POTENTIAL \\
\hline ABTS & 2,2'-AZINO-BIS [3-ETHYLBENTHIAZOLINE-6-SULFONIC ACID] \\
\hline H2S & HYDROGEN SULPHIDE \\
\hline GAE/G & GALLIC ACID EQUIVALENTS PER GRAM \\
\hline
\end{tabular}
given L-NAME $(25 \mathrm{mg} / \mathrm{kg}$, intraperitoneally), Group 2 was given L-NAME and P. speciosa empty pods methanolic extract $(800 \mathrm{mg} /$ $\mathrm{kg}$, orally), Group 3 was given L-NAME and nicardipine $(3 \mathrm{mg} / \mathrm{kg}$, orally) and Group 4 served as negative control. The plasma nitric oxide reduction was inhibited in Group treated with $P$. speciosa (12.33\%), but not with nicardipine (-29.29\%). The blood pressure increase was prevented in groups given $P$. speciosa and nicardipine. However, no difference was seen between the two groups. Consistently, the cardiac ACE, NADPH oxidase activity, as well as cardiac lipid peroxidation content were reduced in groups given $P$. speciosa and nicardipine. These effects were the result of high polyphenol content in P. speciosa. As being reported in previous studies, quercetin exerted hypertensive effect by enhancing nitric oxide production via induction of endothelial nitric oxide synthase [eNOS] phosphorylation [64]. In addition, quercetin also was shown to reduce ACE protein level in endothelial cells [65] and inhibit myocardial NADPH oxidase-dependent superoxide anion generation in hypertensive rats [64].

\section{Conclusion}

P. speciosa or known as stinky bean, is a plant found abundantly in Southeast Asia. Despite of its odorous smell, it has been used both as culinary ingredients and indirectly as a medicine to treat various diseases such as hypertension and urinary tract infection. Various parts of the plant were used, including seed, pod and seed coat. The health benefits of $P$. speciosa are mainly contributed by the phenolic and flavonoid content. The antioxidant property is due to the presence of phenols, flavonoids, hydrogen sulphide and tannin, although the levels differ based on the types of extracts, parts of the plant, plantation and post-harvest handling. P. speciosa also has hypoglycemic effect by inhibiting $\alpha$-glucosidase, $\alpha$-amylase and pancreatic lipase. The effect was due to the synergistic effect of $\beta$-sitosterol and stigmasterol, and by a compound known as stigmast-4-en-3-one. The antitumor activity was exhibited more in pericarp, seed coat and empty pods, compared to the seed of the plant. P. speciosa demonstrated antimicrobial activity against both Gram positive and negative pathogen, although the effect was less potent in the latter. $P$. speciosa inhibit inflammatory markers by blocking the NFKB and MAPK pathways, prevent plasma nitric oxide loss, as well as inhibiting heart angiotensin-converting enzyme. We found that limited animal study and absent of clinical trial was done in evaluating the medicinal effects of Parkia speciosa. Thus, future animal and human studies are needed to strengthen evidence of its medicinal effect. male Sprague Dawley rats were divided into 4 groups: Group 1 was 


\begin{tabular}{|c|c|}
\hline $\mathrm{RE} / \mathrm{G}$ & RUTIN EQUIVALENTS PER GRAM \\
\hline IC50 & HALF-MAXIMAL INHIBITORY CONCENTRATION \\
\hline BHT & BUTYLATEDHYDROXY TOLUENE \\
\hline $\mathrm{TE} / \mathrm{G}$ & TROLOX EQUIVALENTS PER GRAM \\
\hline EDTAE/G & ETHYLENEDIAMINETETRAACETIC ACID EQUIVALENT/G DRY WEIGHT \\
\hline FESO4 & FERROUS SULFATE \\
\hline $\mathrm{H}_{2} \mathrm{O}_{2}$ & HYDROGEN PEROXIDE \\
\hline FDPSP & FREEZE DRIED P. SPECIOSA POD \\
\hline TPC & TOTAL PHENOLIC CONTENT \\
\hline TFC & TOTAL FLAVONOID CONTENT \\
\hline \%DPPHSC & PERCENTAGE DPPH WHICH WAS SCAVENGED \\
\hline \%ABTSSC & PERCENTAGE ABTS WHICH WAS SCAVENGED \\
\hline EC50 & HALF MAXIMAL EFFECTIVE CONCENTRATION \\
\hline DADS & DIALLYL DISULPHIDE \\
\hline DATS & DIALLYL TRISULPHIDE \\
\hline \multicolumn{2}{|l|}{ BCU } \\
\hline MCF- 7 & MICHIGAN CANCER FOUNDATION-7 \\
\hline DATS- E & DATS EQUIVALENT \\
\hline CCA & CUPRIC ION CHELATING CAPABILITIES \\
\hline TEACDPPH & TROLOX EQUIVALENT ANTIOXIDANT CAPACITY DPPH \\
\hline TEACFRAP & TROLOX EQUIVALENT ANTIOXIDANT CAPACITY FRAP \\
\hline CMC & CARBOXYMETHYLCELLULOSE \\
\hline MDA & MALONDIALDEHYDE \\
\hline GSH & TOTAL GLUTATHIONE \\
\hline SOD & SUPEROXIDE DISMUTASE \\
\hline PPL & PORCINE PANCREATIC LIPASE \\
\hline BW & BODY WEIGHT \\
\hline EBV & EPSTEIN-BARR VIRUS \\
\hline PBMC & PERIPHERAL BLOOD MONONUCLEAR CELL \\
\hline XTT & 2,3-BIS-(2-METHOXY-4-NITRO-5-SULFOPHENYL)-2H-TETRAZOLIUM-5-CARBOXANILIDE \\
\hline HUVEC & HUMAN UMBILICAL VEIN ENDOTHELIAL CELLS \\
\hline VEGF & VASCULAR ENDOTHELIAL GROWTH FACTOR \\
\hline EA & EARLY ANTIGEN EA \\
\hline IR & INHIBITORY RATE \\
\hline $\mathrm{CV}$ & CELL VIABILITY \\
\hline VCE/ $100 \mathrm{G}$ & VITAMIN C EQUIVALENT / $100 \mathrm{G}$ \\
\hline TCA & THIOPROLINE OR THIAZOLIDINE-4-CARBOXYLIC ACID \\
\hline AG NPS & SILVER NANOPARTICLES \\
\hline ACE & ANGIOTENSIN-CONVERTING ENZYME \\
\hline TNF-A & TUMOR NECROSIS FACTOR-A \\
\hline L-NAME & N(G)-NITRO-L-ARGININE METHYL ESTER \\
\hline NFKB) P65 & NUCLEAR FACTOR KAPPA B CELL \\
\hline P38 MAPK & P38 MITOGEN-ACTIVATED PROTEIN KINASE \\
\hline INOS & INDUCIBLE NITRIC OXIDE SYNTHASE \\
\hline COX-2 & CYCLOOXYGENASE-2 \\
\hline VCAM-1 & VASCULAR CELL ADHESION MOLECULE-1 \\
\hline NADPH & NICOTINAMIDE ADENINE DINUCLEOTIDE PHOSPHATE HYDROGEN \\
\hline ENOS & ENDOTHELIAL NITRIC OXIDE SYNTHASE \\
\hline
\end{tabular}




\section{Acknowledgement}

We would like to thank the Director General of Health Malaysia for his permission to publish this article. We are also grateful to the Director of the Institute for Medical Research (IMR), "Selangor" for the continuous support and encouragement. We thank Ms Sumarni Mohd Ghazali from Epidemiology and Bio-Statistic Unit, IMR for editing, proofreading and reviewing the manuscript.

\section{References}

1. Al Batran R, Al-Bayaty F, Jamil Al-Obaidi MM, Abdualkader AM, Hadi HA Ali HM, et al. (2013) In Vivo Antioxidant and Antiulcer Activity of Parkia speciosa Ethanolic Leaf Extract against Ethanol-Induced Gastric Ulcer in Rats. PLoS One 8(5): 2-12.

2. Mimosoideae F(1826) Parkia speciosa Parkia speciosa Hassk 0: 1-5.

3. Tangkanakul P, Trakoontivakorn G (2005) Extracts of Thai Indigenous Vegetables as Rancid Inhibitor in a Model System. Kasetsart J 39(2): 274 283.

4. Lim TK (2016) Edible Medicinal and Non-Medicinal Plants. 10: 1-659.

5. Ghasemzadeh A, Jaafar HZE, Bukhori MFM, Rahmat MH, Rahmat A (2018) Assessment and comparison of phytochemical constituents and biological activities of bitter bean (Parkia speciosa Hassk.) collected from different locations in Malaysia. Chem Cent J 12(1): 1-9.

6. Sonia N, R Dsouza, M Alisha(2018) Pharmacological evaluation of Parkia speciosa Hassk. for antioxidant, anti-inflammatory, anti-diabetic and anti-microbial activities in vitro. Int J Life Sci : 49-59.

7. Hasim, Faridah DN, Kurniawati DA (2015) Antibacterial activity of Parkia speciosa Hassk. peel to Escherichia coli and Staphylococcus aureus bacteria. J Chem Pharm Res 7(4): 239-243.

8. Musa NLW, Zain WZ, Kassim J, Karim SA (2012) Premilinary Studies on Phytochemical Screening of Ulam and Fruit from Malaysia. E-Journal Chem 8(1): 285-288.

9. Balaji K, Devi T, Sikarwar MS, Fuloria S (2015) Phytochemical analysis and in vitro antioxidant activity of Parkia speciosa. Int J Green Pharm 9(4): 50-54.

10. Sihombing JR, Dharma A, Chaidir Z, Fachrial E, Munaf E (2015) Research Article Phytochemical screening and antioxidant activities of 31 fruit peel extract from Sumater 7(11): 190-196.

11. Jamaluddin F, Mohameda S, Lajis MN (1995) Hypoglycaemic effect of Stigmast-4-en-3-one, from Parkia speciosa empty pods. Food Chem 54(1): 9-13.

12. Rahman NNNA, Zhari S, Sarker MZI, Ferdosh S, Yunus MAC, et al. (2012) Profile of Parkia speciosa hassk metabolites extracted with SFE using FTIR-PCA method. J Chinese Chem Soc 59(4): 507-514.

13. Akerele 0 (1993). Nature's Medicinal Bounty: don't throw it away. World Health Forum 14(4): 390-395.

14. Samuel AJSJ, Kalusalingam A, Chellappan DK, Gopinath R, Radhamani S, Husain HA, et al (2010) Ethnomedical survey of plants used by the Orang Asli in Kampung Bawong, Perak, West Malaysia. J Ethnobiol Ethnomed 6: 1-6.

15. Zaini N, Mustaffa F(2017) Review: Parkia speciosa as Valuable, Miracle of Nature. Asian J Med Heal 2(3): 1-9.

16. Kamisah Y, Othman F, Qodriyah HMS, Jaarin K (2013) Parkia speciosa Hassk.: A Potential Phytomedicine Evidence-Based Complement Altern Med 2013: 1-9.

17. Aisha AFA, Abu-Salah KM, Alrokayan SA, Ismail Z, et al. (2012) Evaluation of antiangiogenic and antoxidant properties of Parkia speciosa Hassk extracts. Pak J Pharm Sci 25(1): 7-14.
18. Wonghirundecha S, Benjakul S, Sumpavapol P (2014) Total phenolic content, antioxidant and antimicrobial activities of stink bean (Parkia speciosa Hassk) pod extracts. Songklanakarin J Sci Technol 36(3): 300308.

19. Siow HL, Gan CY (2013) Extraction of antioxidative and antihypertensive bioactive peptides from Parkia speciosa seeds. Food Chem 141(4): 3435-3442.

20. Reihani SFS, Azhar ME (2012) Antioxidant activity and total phenolic content in aqueous extracts of selected traditional Malay salads (Ulam). Int Food Research J 19(4): 1439-1444.

21. Liang D, Wang C, Tocmo R, Wu H, Deng LW, Huang D (2015) Hydrogen sulphide $\left(\mathrm{H}_{2} \mathrm{~S}\right)$ releasing capacity of essential oils isolated from organosulphur rich fruits and vegetables. J Funct Foods 14: 634-640.

22. Wong SP, Leong LP, William Koh JH (2006) Antioxidant activities of aqueous extracts of selected plants. Food Chem 99(4): 775-783.

23. Ko HJ, Ang LH, Ng LT(2014) Antioxidant activities and polyphenolic constituents of bitter bean Parkia speciosa. Int J Food Prop 17(9): 19771986.

24. Gan CY, Latiff AA (2011) Antioxidant Parkia speciosa pod powder as potential functional flour in food application: Physicochemical properties' characterization. Food Hydrocoll 25(5): 1174-1180.

25. Tanasorn T, Suphan S,Anusorn R, Attakorn P (2012) Inhibitory activity of Heinz body induction in vitro antioxidant model and tannin concentration of Thai mimosaceous plant extracts. J Med Plants Res. 6(24): 40964101.

26. Maisuthisakul P, Pasuk S, Ritthiruangdej P (2008) Relationship between antioxidant properties and chemical composition of some Thai plants. J Food Compos Anal 21(3): 229-240.

27. Udenigwe CC, Aluko RE (2011) Chemometric analysis of the amino acid requirements of antioxidant food protein Hydrolysates. Int J Mol Sci 2(5): 3148-3161.

28. Kimura Y, Goto Y, Kimura H (2010) Hydrogen sulphide increases glutathione production and suppresses oxidative stress in mitochondria. Antioxid Redox Sign 12(1): 1-13.

29. Benavides GA, Squadrito GL, Mills RW, Patel HD, Isbell TS, et al. (2007) Hydrogen sulfide mediates the vasoactivity of garlic. Proc Natl Acad Sci 104(46): 17977-17982.

30. Chuah SC, Moore PK, Zhu YZ (2019) S -allylcysteine mediates cardioprotection in an acute myocardial infarction rat model via a hydrogen sulfide-mediated pathway pp. 2693-2701.

31. Christopher MM, White JG, Eaton JW (1990) Erythrocyte Pathology and Mechanisms of Heinz Body-mediated Hemolysis in cats. Vet Pathol 27(5): 299-310.

32. Lopes GKB, Schulman HM, Hermes-lima M (1999) Polyphenol tannic acid inhibits hydroxyl radical formation from Fenton reaction by complexing ferrous ions. Biochim Biophys Acta 1472(1-2): 142-152.

33. Dursun H, Bilici M, Albayrak F, Ozturk C, Saglam MB, et al. (2009) Antiulcer activity of fluvoxamine in rats and its effect on oxidant and antioxidant parameters in stomach tissue. BMC Gastroenterol 9: 1-10.

34. Repetto MG, Llesuy SF (2002) Antioxidant properties of natural compounds used in popular medicine for gastric ulcers. Brazilian J Med Biol Res 35(5): 523-534

35. La Casa C, Villegas I, Alarcon De La Lastra C, Motilva V, Martin Calero MJ et al. (2000) Evidence for protective and antioxidant properties of rutin a natural flavone, against ethanol induced gastric lesions. J Ethnopharmacol 71(1-2): 45-53.

36. Johansen JS, Harris AK, Rychly DJ, Ergul A (2005) Oxidative stress and the use of antioxidants in diabetes: Linking basic science to clinical pratice. Cardiovasc Diabetol 4: 1-11. 
37. Jamaludin F, Mohamed S (1993) Hypoglycemic effect of extracts of Petai Papan (Parkia speciosa, Hassk). Pertanika J. Trop. Agric. Sci 16(3): 161165.

38. Jamaluddin F, Mohamed S, Lajis MN (1994) Hypoglycaemic effect of Parkia speciosa seeds due to the synergistic action of $\beta$-sitosterol and stigmasterol. Food Chem 49(4): 339-345.

39. Tunsaringkarn T, Rungsiyothin A, Ruangrungsi N (2008) $\alpha$-glucosidase inhibitory activity of Thai mimosaceous plant extracts. J Health Res 22(1): 29-33

40. Kakavanos R, Hopwood JJ, Lang D, Meikle PJ, Brooks DA (2006) Stabilising normal and mis-sense variant $\alpha$-glucosidase. FEBS Lett 580(18): 4365-4370.

41. Murakami A, Ali AM, Mat-Salleh K, Koshimizu K, Ohigashi H (2005) Screening for the In Vitro Anti-tumor-promoting Activities of Edible Plants from Malaysia. Biosci Biotechnol Biochem 64(1): 9-16.

42. Tangkanakul P, Trakoontivakorn G, Saengprakai J, Auttaviboonkul P, Niyomwit B, et al. (2011) Antioxidant capacity and antimutagenicity of thermal processed thai foods. Japan Agric Res 45(2): 211-218

43. Suvachittanont W, Kurashima Y, Esumi H, Tsuda M (1996) Formation of thiazolidine-4-carboxylic acid (thioproline), an effective nitrite-trapping agent in human body, in Parkia speciosa seeds and other edible leguminous seeds in Thailand. Food Chem 55(4): 359-363.

44. Tunsaringkarn T, Suwansaksri J, Rungsiyothin A, Palasuwan A (2014) Cell proliferation activities in vitro model of Thai mimosaceous extracts. J Chem Pharm Res 6(1): 507-511.

45. Tsuda M, Kurashima Y (1991) Nitrite-trapping Capacity of Thioproline in The Human Body. IARC Sci Publ 105: 123-128.

46. Nakatogawa H and Ohsumi Y (2008) Starved cells eat ribosomes. Nat Cell Biol 10: 505- 507.

47. Uyub AM, Nwachukwu IN, Azlan AA and Fariza SS (2010) In vitro antibacterial activity and cytotoxicity of selected medicinal plant extracts from Penang island Malaysia on metronidazole resistant Helicobacter pylori and some pathogenic bacteria. Ethnobotany Research and Applications 8: 95-106.

48. Sakunpak A, Panichayupakaranant P (2012) Antibacterial activity of Thai edible plants against gastrointestinal pathogenic bacteria and isolation of a new broad spectrum antibacterial polyisoprenylated benzophenone, chamuangone. Food Chem 130(4): 826-831.

49. Gmelin R, Susilo R, Fenwick GR (1981) Cyclic polysulphides from Parkia speciosa. Phytochemistry 20(11): 2521-2523.

50. Musa N, Wei LS, Seng CT, Wee W, Leong LK (2008) Potential of Edible Plants as Remedies of Systemic Bacterial Disease Infection in Cultured Fish. Glob J Pharmacol 2(2): 31-36.

51. Randhir R, Ms YL, Shetty K (2004) Phenolics, their antioxidant and antimicrobial activity in dark germinated fenugreek sprouts in response to peptide and phytochemical elicitors. Asia Pac J Clin Nutr 13(4): 295-307.
52. Wonghirundecha S, Sumpavapol P (2012)Antibacterial Activity of Selected Plant By-products Against Food- borne Pathogenic Bacteria. Int Conf Nutr Food Sci 39(1): 116-20.

53. Thitilertdecha N, Teerawutgulrag A, Rakariyatham N (2008) Antioxidant and antibacterial activities of Nephelium lappaceum L. extracts. LWT Food Sci Technol 41(10): 2029-2035.

54. Suklampoo L, Thawai C, Weethong R, Champathong W, Wongwongsee W (2014) Antimicrobial Activities of Crude Extracts from Pomelo Peel of Khao-nahm-peung and Khao-paen Varieties. KMITL Sci Technol J 12(1).

55. Mokbel MS, Hashinaga F (2009) Antibacterial and Antioxidant Activities of Banana (Musa, AAA cv. Cavendish) Fruits Peel. Am J Biochem Biotechnol1(3): 125-131.

56. Fatimah I (2016) Green synthesis of silver nanoparticles using extract of Parkia speciosa Hassk pods assisted by microwave irradiation. J Adv Res 7(6): 961-969.

57. Mustafa NH, Ugusman A, Jalil J, Kamisah Y (2018) Anti-inflammatory property of Parkia speciosa empty pod extract in human umbilical vein endothelial cells. J Appl Pharm Sci 8(1): 152-158.

58. Gui JS, Jalil J, Jubri Z, Kamisah Y (2019) Parkia speciosa empty pod extract exerts anti-inflammatory properties by modulating $\mathrm{NFKB}$ and MAPK pathways in cardiomyocytes exposed to tumor necrosis factor- $\alpha$. Cytotechnology 71(1): 79-89.

59. Kamisah Y, Zuhair JSF, Juliana AH, Jaarin K (2017) Parkia speciosa empty pod prevents hypertension and cardiac damage in rats given $\mathrm{N}(\mathrm{G})$-nitro-L-arginine methyl ester. Biomed Pharmacother 96(8): 291-298.

60. Karunaweera N, Raju R, Gyengesi E (2015) Plant polyphenols as inhibitors of NF- $\mathrm{KB}$ induced cytokine production- a potential anti-inflammatory treatment for Alzheimer's disease? Front Mol Neurosci 8(6): 1-5.

61. Sorriento D, Santulli G, Fusco A, Anastasio A, Trimarco B, et al. (2010) Intracardiac injection of AdGRK5-NT reduces left ventricular hypertrophy by inhibiting NF-KB-Dependent hypertrophic gene expression. Hypertension 56(4) 696-704.

62. Huang GJ, Huang SS, Deng JS (2012) Anti-inflammatory activities of inotilone from Phellinus linteus through the inhibition of MMP-9, NF- $\mathrm{KB}$, and MAPK activation in vitro and in vivo. PLoS One 7(5).

63. Martin ED, Felice De Nicola G, Marber MS (2012) New therapeutic targets in cardiology: P38 alpha mitogen-activated protein kinase for ischemic heart disease. Circulation 126(3): 357-368.

64. Galindo P, Gonzalez-Manzano S, Zarzuelo MJ, Gomez-Guzman M, Quintela AM, et al. (2012) Different cardiovascular protective effects of quercetin administered orally or intraperitoneally in spontaneously hypertensive rats. Food Funct 3(6): 643-650.

65. Huang WY, Fu L, Li CY, Xu LP, Zhang LX, et al. (2017) Quercetin, Hyperin, and Chlorogenic Acid Improve Endothelial Function by Antioxidant, Antiinflammatory, and ACE Inhibitory Effects. J Food Sci 82(5): 1239-1246. 